\title{
4Collaborative Web Based Project MANAGEMENT SOFTWARE
}

\author{
A.R. Khan ${ }^{1}$, Rquaiya Khan ${ }^{2}$, Trimbak R Sontakke ${ }^{3}$, Shraddha R Khonde ${ }^{4}$, \\ Revati Wahul ${ }^{5}$, Mahtab alam ${ }^{6}$ \\ ${ }^{1,4,5}$ M.E.S College of Engineering, Pune -411001 \\ 1 ahmed.khan@mescoepune.org \\ 4 shraddha.khonde@mescoepune.org \\ 5 rmwahul@mescoepune. org \\ ${ }^{2}$ Uttrakhand University, Uk. \\ ruqaiyamaqsoodegmail.com \\ ${ }^{3}$ Siddhant College of Engineering. \\ trsontakke@gmail.com \\ ${ }^{3}$ Poona College, Pune. \\ mahtabalamehotmail.com
}

\begin{abstract}
Project Management Software dramatically improves performance and the communication between the distributed and remote teams. Project Management software heightens the visibility and control of the application development lifecycle-giving a better control over the entire development process, from the management stage through development. The goal of Project Management Software is to produce a product that is delivered on time, within the allocated budget, and with the capabilities expected by the customer. Project management software is basically a properly managed project has a clear, communicated, and managed set of goals and objectives, whose progress is quantifiable and controlled. Resources are used effectively and efficiently to produce the desired product. A project usually has a communicated set of processes that cover the daily activities of the project, forming the project framework. As a result, every team member understands their roles, responsibilities and how they fit into the big picture thus promoting the efficient use of resources.
\end{abstract}

\section{KEYWORDS}

Project Management, Software engineering, SOA

\section{INTRODUCTION}

Lack of manageability and creeping projects scope are two of the worst problems plaguing IT organizations today. Not only can these problems be costly, they can be deadly to your ultimate business objectives. To compete, your need to take out Uncertainty with technologies that improve definition, purpose, and scope. The PMS Solution will give you-and your team- greater real-time insight into project requirements, and the inevitable changes of the scope that cross the boundaries of the distributed teams. This visibility allows each member of the team to share in project expectations from the outset, creating an alignment of thinking that leads to higher productivity and managed control over the development process. The PMS allows you to move into the future without abandoning the past it provides interoperability that is fundamental to the application lifecycle. Globalization for many companies today, around-the-clock, nonstop design Natarajan Meghanathan, et al. (Eds): SIPM, FCST, ITCA, WSE, ACSIT, CS \& IT 06, pp. 417-423, 2012. (C) CS \& IT-CSCP 2012 
and development sounds too good to be true. That's precisely the point, because the reality is this: disparate groups, multiple agendas, missed opportunities, failed communication and project handoffs that are far from seamless. So how do you keep multiple teams- distributed around the campus or around the globe- Working in concert and focused on the end goal? First, you need an integrated environment from managing change and configuration requirements and a system that is designed to give you visibility into the development process-one that will help you maintain control of the application lifecycle. Project Management Software will be used to collect the information from the different levels of software development lifecycle Fig [1]. And different peoples involved in the project/product development. It provides Status and Reports of the different levels of the project/product; it will monitor the entire software development life cycle and provide status and reports at the different levels [1], It will maintain the details of the client and the developer interaction as all the documentation work will be done by both the client and the software development team who are working on the client project/product. The information updating is done by the authorized person of the company who will be in contact with the client and with the development team basically the project manager can manage all his developers activities and the client can monitor the project managers as well as the developers activities without wasting time and money for traveling. The client who is giving the project/product to be developed to the company can view the documentation that is done. As the client will have a tight control on the different parts of the project/product and also the client will get all the status and report of what has been done in the entire day, week, month related to his project he can also view the manpower details and how many people are working on his project, the status of the person who has been allotted for his project/product can be monitored. As this software will provide help to the Software Development Industry the scope of the project can also be extended to the other small scale and large scale industries. This product monitors the activities of the entire software development life cycle.

\section{Requirement Analysis}

\section{Prototyping}

\section{Design}

\section{Development}

\section{Testing}

\section{Documentation}

\section{Development}

\section{Maintenance}

The goal of Project Management Software is to produce a product that is delivered on time, within the allocated budget, and with the capabilities expected by the customer. Project management software is basically a properly managed project has a clear, communicated, and managed set of goals and objectives, whose progress is quantifiable and controlled and whose resources are used effectively to efficiently produce the desired product [2]. When properly managed, a project usually has a communicated set of processes that cover the daily activities of the project, forming the project framework. As a result, every team member understands their roles and responsibilities and how they fit into the big picture, thus promoting the efficient use of resources. Project Management Software will be used to collect the information from the different levels of software development and different peoples involved in the project and product 
development. This software will handle all the activities starting from the Inquiry from by the client to the Planning, completion and delivery of the product made by the company to the client. All the activities will be monitored and will be documented which can also be viewed by the company who has made the product for the client along with all its details of the product and with information that was required in building the product and also it can be viewed by the client on the client side as the client will be able to view all the details of his product and also will be able to interact with proof with the team members working on this product. The client will come to know the exact manpower employed and the time duration spend by each employ that is employed on his product development. So that there will not be any hiding of information from the company who is developing the product for the Client. The collaborative information, which will be gathered, will be visible to the client and the company who is developing the Product. Hither to the information on this topic is scanty thus it is decided to investigate this topic in more details so as to minimize the cost of the product developed and also to save the time required in the development of the project/product for any client.

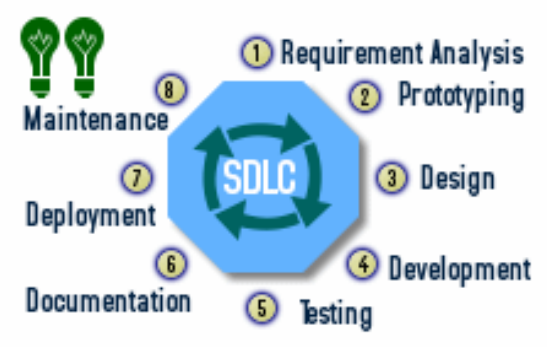

Fig 1: Software Development Life Cycle.

\subsection{Why PMS}

PMS (Project Management Software) Web-based software increases performance, productivity and efficiency within an organization. Project management capabilities will enable organizations to support their business processes in a simple, but effective manner. And helpful portfolio overviews make it easy to manage complex schedules across the organization [3].

\section{a. Easy Client Support and Registration}

The PMS provides a vital facility for the customers and the clients of the company which are registered with the software company. Software development is based on accurately built and matured Software Development Life Cycle. A dynamic application can increase the client's productivity and cater to the Clients ever- changing requirements. It will give the client a management tool to improve the performance of the clients business.

\section{b. Easy Data Management}

The PMS Allows easy adding of tasks, assign users, set durations, Testing and more ?All from a GUI layout that is easy to understand and use.

\section{c. Views and Reporting}

As a manager or executive it's important to know where your projects stand. You can analyze multiple projects with PMS Status Reports, Test rollup reports, Project group lists and much more.

\section{d. User and Project Schedules}

Every user can have their schedule defined at PMS. With this information, project timelines take 
into consideration the schedule of the person doing the work so that team members are evenly tasked and accurate completion predictions are made the entire software Development Life cycle is distributed in the time frame with each phase in the software development life cycle having a start date and a end date

\section{Domain Area of Project}

The domain area of the project is the web based application the multi-tier architecture is the main consideration of .Net 2005 that allows creating the system. The PMS allows managing and maintaining the project Status and reports that are very useful for better productivity and also less time consuming.

\section{a. Microsoft .NET Framework Common Language Runtime}

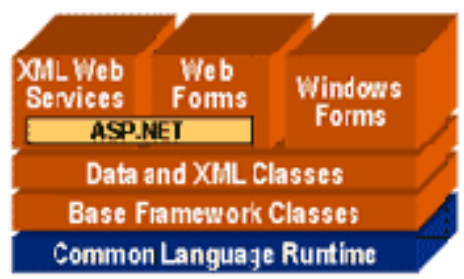

Figure 2. Common Language runtime

The (CLR) Fig [2] is responsible for run-time services such as language integration, security enforcement, and memory, process, and thread Management. In addition, the CLR fig [2] has a role at development time when features such as life-cycle management, strong type naming, cross-language exception handling, and dynamic binding reduce the amount of code that a developer must write to turn business logic into a reusable component.

\section{WORKING EXPLANATION}

Project Management software can be deployed on to the IIS server and different persons sitting on there matching can access this application as PMS is a web based software it contains different sections that can be used for managing and mentioning the software project. Basically this software contains the new registration screen that can be used to register for using the functionalities and features of this system after the user or the client is registered he can log into the system but can not access the different functionalities of the software unless the administrator provides him the rights to access the different functionalities of the software system. Once the client has registered successfully a message will be send to the administrator who will provide rights to the client to access the different parts of the project the administrator will give rights to the client to access the screens that the client is supposed to see and access. The employee of the company can also register with PMS while employee registration the employee has to specify his designation. The PMS allows you to manage the entire software Development Life cycle by planning and managing the different phases of the software development lifecycle. The client information screens provide the client to register and also maintain the details of the client for the company persons. The client can also send a inquiry for the project to the company persons. A proposal can be send by the company person to the client requesting for the project. The planning and Execution part of PMS allows to plan the project development and also allows us to manage the planned schedule the authorized person or the project manager can plan the details of the software project and the check the completion of the particular phase of the software life cycle is on time or not also the modules and sub modules details of the software can be maintained and managed. 
The project-testing module allows the testers to test and list the issues in the project under test a bug details can be maintained as the PMS is a web base software the details of the bug can be viewed by the developer and can be cured immediately as and when the bug is reported by the testers The project release module allows the release of the project to the client once all it maintains the details of the pending issues of the project, payment made by the client to the company developing the project. The pending issues are those issues that are in work still the client wants the delivery of the project. The pending issues can be viewed by the developer so that they can be cured as soon as possible.

The administrative section allows the administrator of the system to give rights to the usres and allows registrations of the new employees the administrator can register the new employee also the admin can provide access to the client for the different functionalities of PMS from this module.

\section{DESIGN OF THE SOFTWARE}

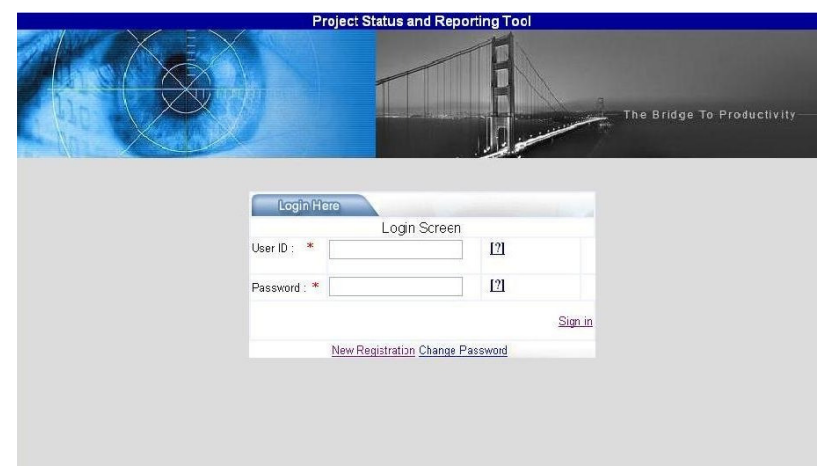

Fig 3. Login Screen of Project Management

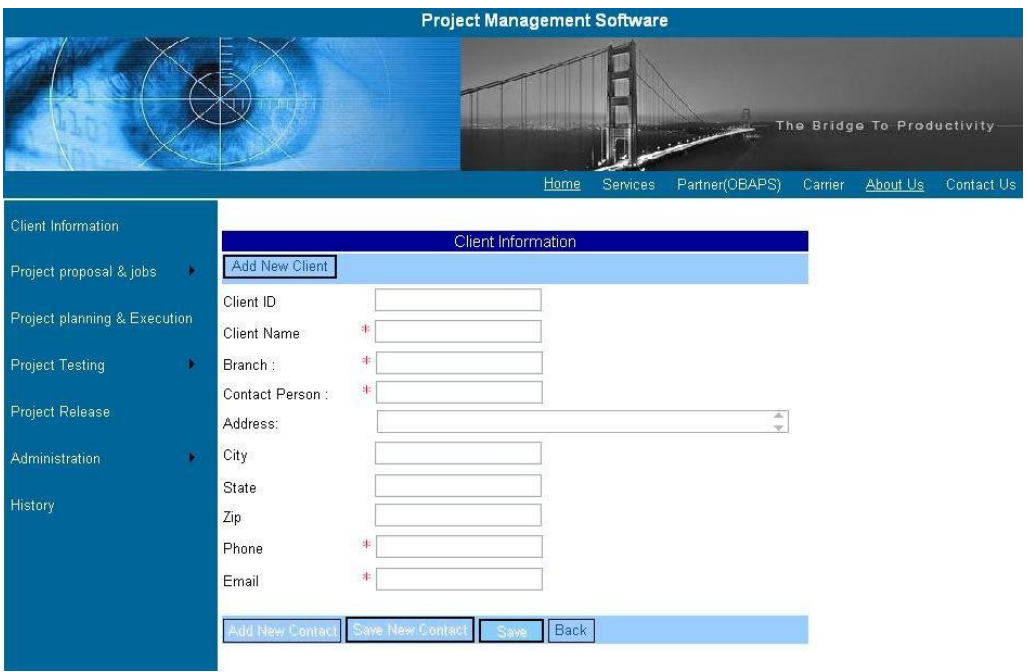

Fig 4. New User Registration Screen. 


\section{CONCLUSION}

Last but not the least With PMS, Project Management software dramatically improves performance and the communication between the distributed and remote teams, heighten the visibility and control of your application development lifecycle-giving you better control over the entire development process, from the management stage through development. With PMS move into the future without abandoning the past it provides interoperability that is fundamental to the application lifecycle. Globalization for many companies today, around-the-clock, nonstop design and development sounds too good to be true. So how do you keep multiple teams-distributed around the campus or around the globe-working in concert and focused on the end goal? First, you need an integrated environment from managing change and configuration requirements and a system that is designed to give you visibility into the development process-one that will help you maintain control of the application lifecycle which is achieved by project management software. Heather to it was decided to investigate this topic in more details.

\section{ACKNOWLEDGEMENTS}

I would like to thank "Ruqaiya Ahmad Raza Khan" for constantly helping me and guiding me for the preparation of this paper and my research work. I would also like to thank "Prof. Dr. Trimbak $\mathrm{R}$ Sontakke" for giving me this opportunity to present this paper at international level and providing me with the necessary resources as and when required.

\section{REFERENCES}

[1] Abdullah Saeed Bani Ali "A Study of Project Management System Acceptance" 0-7695-22688/05 IEEE SOFTWARE, Proceedings of the 38th Annual Hawaii International Conference on System Sciences (HICSS'05) - Track 8 - Volume 08 IEEE 2005.

[2] Arthur B. Pyster, Richard H. Thayer, "Software Engineering Project Management 20 years Later" IEEE SOFTWARE Volume 22, Issue 5 (September 2005) Pages: 18 - 21.

[3] Marc Frappier, Mario Richard "SMP: A Process-Driven Approach To Project Management" 07695-2056-1 IEEE SOFTWARE Proceedings of the 37th Annual Hawaii International Conference On System Sciences (HICSS'04) - Track 8 - Volume 8 IEEE 2004 Page: 80253.3.

\section{Authors}

Prof. Mr. Ahmad Raza Khan, Assistant Professor, M.E.S College of Engineering Pune- 411001.

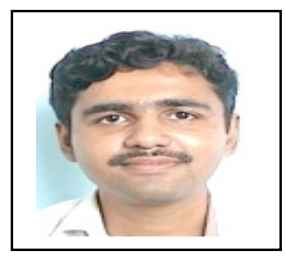

\section{Co-Authors}

Mrs. Ruqaiya Ahmad Raza Khan, Student, Uttrakhan University

Nanital.

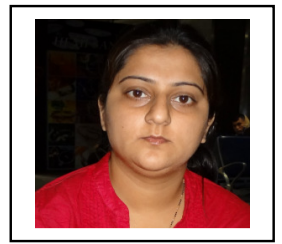




\section{Co-Authors}

Porf. Dr. Trimbak R Sontakke, Principal,

Siddhant College of Engineering, Sudumbare Pune.

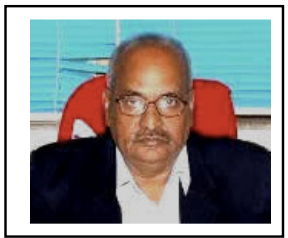

\section{Co-Authors}

Porf. Mrs.Shraddha R Khonde, Assistant Professor,

M.E.S College of Engineering, Pune- 411001.

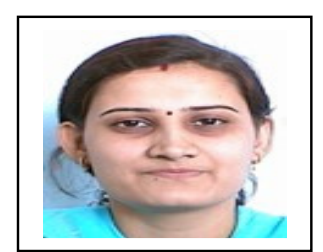

\section{Co-Authors}

Porf. Ms.Revati Wahul,

Assistant Professor,

M.E.S College of Engineering,

Pune- 411001.

\section{Co-Authors}

Porf. Mahtab Alam,

H.O.D,

Poona College,

Pune- 411001.
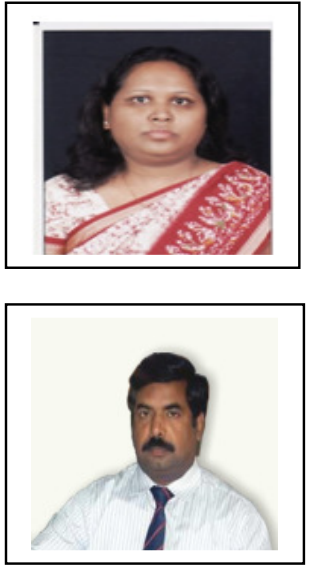